\title{
Solubility of Bifonazole in Four Binary Solvent Mixtures: Experimental Measurement and Thermodynamic Modeling
}

\author{
Jianqiang Zhang ${ }^{1}$, Chunjuan Huang ${ }^{2}$, Renjie $\mathrm{Xu}^{*}, 2$ \\ ${ }^{1}$ Henan Provincial Key Laboratory of Surface \& Interface Science, Zhengzhou University of Light Industry, \\ Henan 450001, People's Republic of China \\ ${ }^{2}$ Guangling College, Yangzhou University, Yangzhou, Jiangsu 225000, People's Republic of China \\ Corresponding author. Phone: + 86514 87993918; Fax: + 8651487994009. \\ E-mail address: xurenjie126@163.com
}




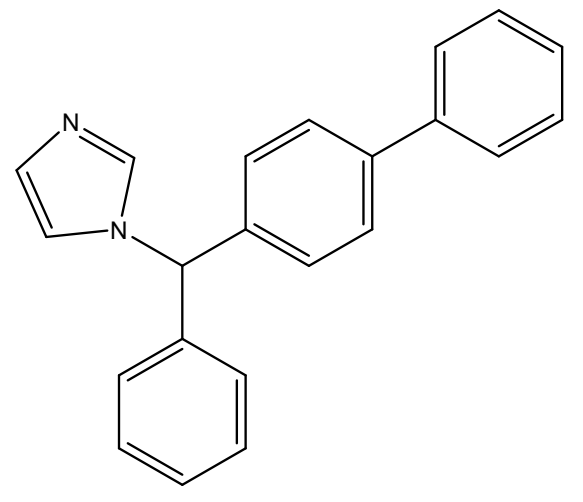

Fig. S1. Chemical structure of bifonazole. 


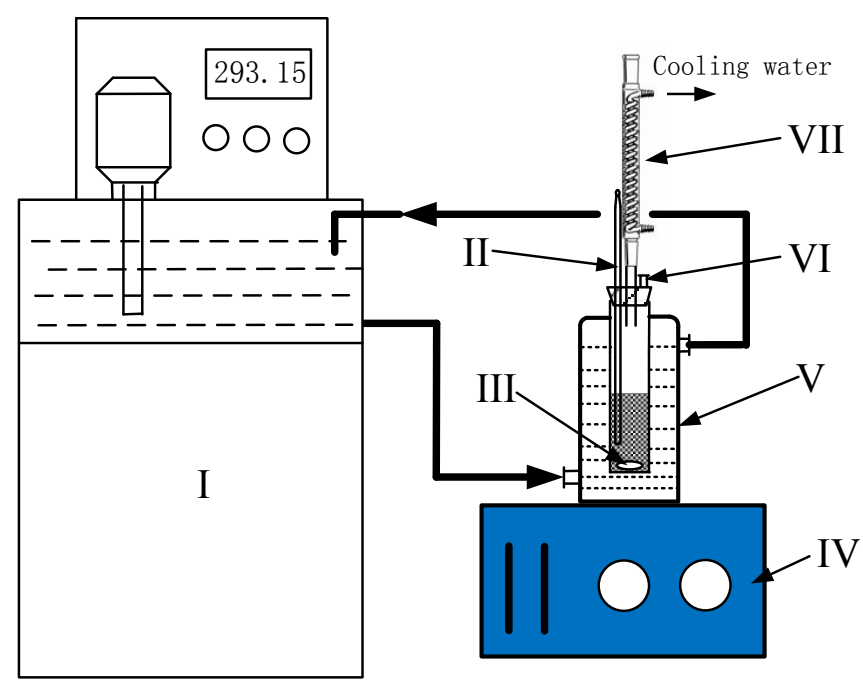

Fig. S2. Schematic diagram of experimental apparatus: I, smart thermostatic water bath; II, mercury-in-glass thermometer; III, magnetic stirrer; IV, stirrer controller; V, jacketed glass vessel; VI, sampling port; VII, condenser. 


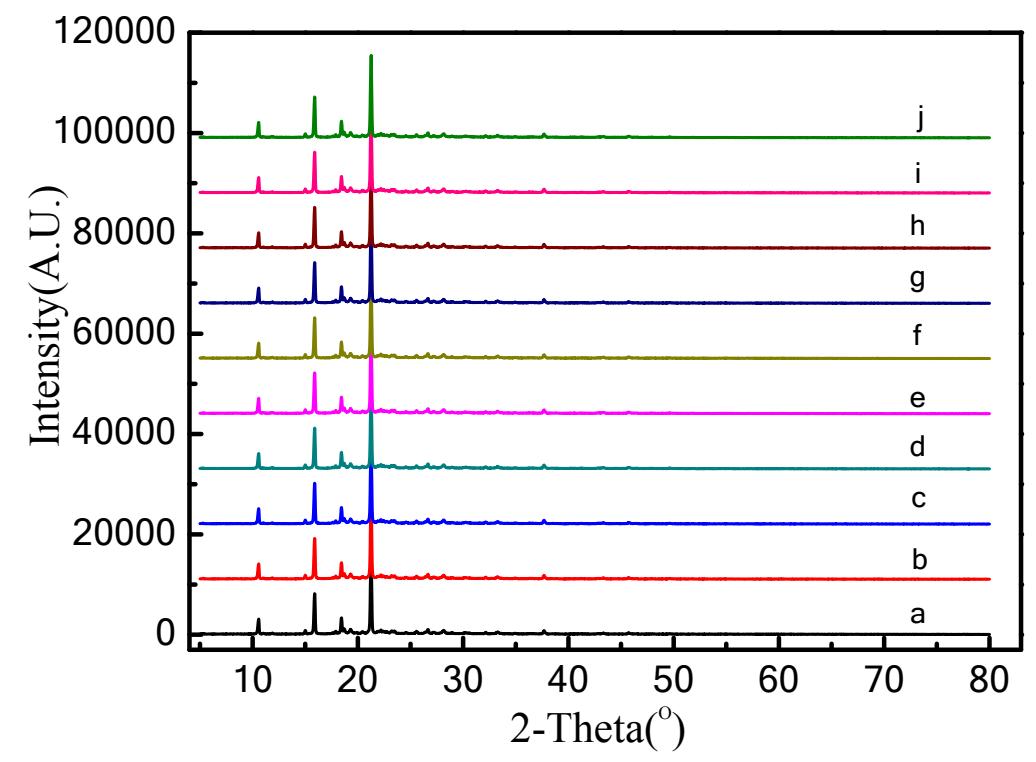

Fig. S3. XRD patterns of bifonazole: (a) raw material; (b) crystallized in neat methanol; (c) crystallized in neat PG; (d) crystallized in neat $n$-propanol; (e) crystallized in neat isopropanol; (f) crystallized in neat water; (g) crystallized in methanol + water mixture; (h) crystallized in PG + water mixture; (i) crystallized in $n$-propanol + water mixture; (j) crystallized in isopropanol + water mixture. 


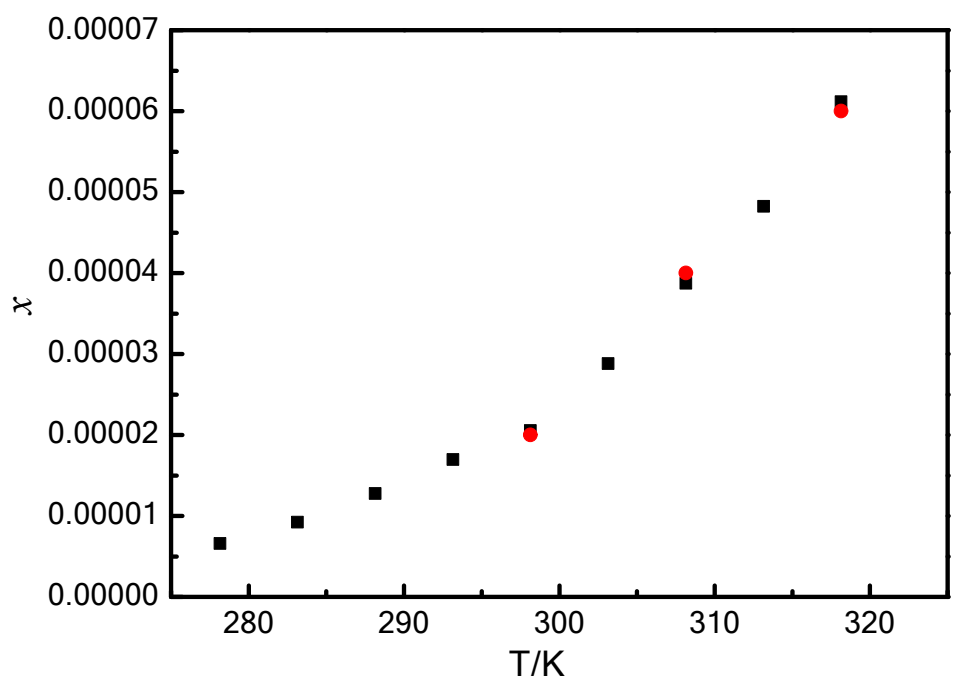

Fig. S4. Mole fraction solubility $(x)$ of bifonazole in water determined in this work and reported in the previous publication: $\mathbf{\square}$, this work; $\boldsymbol{\bigotimes}$, taken from Ref. [1]. 


\section{REFERENCES}

(1) Domańska, U.; Pobudkowska, A.; Pelczarska, A.; Winiarska, T. M.; Gierycz, P. Solubility and pKa of select pharmaceuticals in water, ethanol, and 1-octanol. J. Chem. Eng. Data. 2010, 42, $1465-1472$. 